\title{
DESIGN OF LARGE-SCALE LOGISTICS SYSTEMS USING COMPUTER SIMULATION HIERARCHIC STRUCTURE
}

\author{
Straka, M. ; Lenort, R. ${ }^{* *}$; Khouri, S. ${ }^{* * *} \&$ Feliks, J. \\ *Institute of Logistics, BERG Faculty, Technical University of Kosice, Park Komenskeho 14, \\ 04384 Kosice, Slovakia \\ ** Department of Logistics, Quality and Automotive Technology, ŠKODA AUTO University, \\ Na Karmeli 1457, 29301 Mlada Boleslav, Czech Republic \\ *** Institute of Earth Resources, BERG Faculty, Technical University of Kosice, Park Komenskeho 19, \\ 04384 Kosice, Slovakia \\ ***** Faculty of Management, AGH University of Science and Technology, Gramatyka 10, \\ 30-059 Krakow, Poland \\ E-Mail: martin.straka@tuke.sk, radim.lenort@savs.cz, samer.khouri@tuke.sk, jfeliks@ zarz.agh.edu.pl
}

\begin{abstract}
When designing simulation models of large-scale logistics systems in manufacturing, such as automotive industry or engineering and petrochemical production, creators of these models consider how to properly render the whole system in one simulation model as accurately as possible. One possible approach to designing such models is the application of a hierarchic structure. The structure groups and combines the essential elements of simulation models into larger units. The aim of the paper is to analyse and identify the potential of the computer simulation using a hierarchic structure for increasing the effectiveness of designing large-scale logistics systems in manufacturing. A case study from the automotive industry using EXTENDSIM software environment is used for that purpose.
\end{abstract}

(Received in August 2017, accepted in January 2018. This paper was with the authors 2 weeks for 1 revision.)

Key Words: Discrete Event Simulation, Hierarchic Structure, Large-Scale Logistics System, Manufacturing

\section{INTRODUCTION}

The development of large-scale, robust manufacturing systems resulted from the development of new technologies, which enable the manufacture of products that satisfy unique customer requirements, and also the boom in construction and automotive industries that depend on the supply of basic materials, such as iron, sheet metal and construction chemicals. Designing and testing complex simulation models for such systems is more demanding both in terms of system analysis and initial data collection for the design of models and in terms of verification of the models and validation of the results in practice. One of the possible approaches to designing simulation models of large-scale logistic systems in manufacturing is the application of a hierarchic structure. The basic idea is that individual hierarchic blocks are viewed as black boxes with its inputs and outputs. In this way, even incredibly complex largescale systems can be simplified, which does not affect the capacity to conduct research with models in this form.

The automotive industry is one field where this hierarchic approach bears results. Different customers have different requirements with regards to the interior, colour and security features among others. These various components are purchased from different contracted manufacturers. Only a robust logistics chain can both satisfy these demands and ensure manufacturing flows smoothly and without unnecessary costs. Capturing these largescale systems in detail requires the experience of creators of simulation models as well as advanced simulation software that allow this simulation. 
The article addresses the effective design of simulation models of large-scale logistic systems in manufacturing using hierarchic structures in order to address specific problems arising from practice. The hierarchic structure is a structure that groups and combines the essential elements of simulation models into larger units. While it is possible to design a multi-level hierarchic structure by combining already connected units into even larger units, the so-called "black boxes" principle can also be used. Although black boxes represent operations, departments or entire enterprises, we are only interested in input and output parameters of the examined object and not what is going on inside of the black box.

The aim of the paper is to analyse and identify a potential of the computer simulation using a hierarchic structure for increasing the effectiveness of designing large-scale logistics systems in manufacturing. The aim is met based on a case study from the automotive industry. EXTENDSIM was used as a simulation software.

\section{METHODOLOGICAL BASE}

Simulation, modelling and management as branches have come a long way, but their importance is still sizeable. Simulation is an established analysis method for manufacturing and logistic purposes. It is frequently used when decisions with high risks have to be taken, and the consequences of such decisions are not directly visible, or no suitable analytical solutions are available [1]. Simulation tools are becoming increasingly dynamic to capture the interaction between the level of service and potential revenue generation. Since there are substantial economies of scale in logistics, increased demand offers the potential to reduce cost which, in turn, offers potential incentives to increase demand [2].

\subsection{Simulation in logistics and manufacturing}

The use of simulation for manufacturing systems design and analysis is rightfully recognised by scientists and industrial managers. Traditionally, simulation has been used for offline decision-making. One of the limitations of its use for online decision-making is the considerable amount of time spent in gathering and analysing data. In real-time control, the three key issues are data acquisition, quick response and instantaneous feedback [3]. Simulation experiments can determine the best available trade-off in any particular situation such as achieving the lean logistics aim of minimum reasonable inventory whilst retaining high customer service levels [4].

Business oriented simulations tend to be smaller in scale, involve solitary modellers, normally using a visual interactive modelling tool [5], and the models are often thrown-away on completion of a project. In industrialised countries a large number of industrial organisations simulate their manufacturing systems for solving practical production problems relating to their daily operations [6]. The simulation of manufacturing systems usually requires rather detailed data, concerning the duration of the modelled activities, which determine the quality and reliability of simulation results. Application in industry has shown that these data are usually available for manufacturing [7].

Simulation software is adapted for the needs of simulation. It allows for the design simulation models in such form, so the designed models were representing the simulated systems $[8,9]$. The simulation models allow performing quick changes so said changes reflect changes which can occur in an actual manufacturing system. Implementing experimental design and intelligent search in the simulation optimises simulated tests $[10,11]$. The available production time is crucial for monitoring and adjustment of both the manufacturing process and the design of simulation models [12, 13]. The development of advanced simulation systems has opened new possibilities and significantly supported the trend toward 
streamline manufacturing activities, and thus reduced costs and increased performance of the manufacturing system $[14,15]$.

Business process modelling and business process simulation help to facilitate process thinking [16]. Adopting a supply chain management strategy means applying a business philosophy where more industrial nodes along a logistic network act together in a collaborative environment, pursuing common objectives and continuously exchanging information, while preserving the organisational autonomy of each single unit. A business vision is applied to different industrial processes, e.g., procurement, logistics, marketing, etc. and implementing different policies, e.g., continuous replenishment, co-marketing, etc. [17] with solution methodology as heuristics, statistics, modelling and simulation.

\subsection{Design of simulation models of large-scale logistics systems in manufacturing}

Large-scale systems have traditionally been characterised by large numbers of variables, structure of interconnected subsystems and other features that complicate the control models such as nonlinearities, time delays, and uncertainties. The decomposition of large-scale systems into smaller, more manageable subsystems allows for the implementation of effective decentralisation and coordination mechanisms [18]. A large scale production system often consists of a group of structured organisations to produce a family of complex and customised products in a certain geographic region [19]. There are several crucial characteristics among these industries, and the nature of a large scale production system is influenced by its products. The most common characteristics of a large scale production system are long cycle time, low total throughput and limited buffer space [20].

Before conducting the computer simulation experiment, it is necessary to pay careful attention to the experimental design questions [21]. Balci [22] breaks the early parts of a simulation study down into a number of processes: problem formulation, investigation of solution techniques, system investigation, model formulation, model representation and programming. This part of a simulation study is among the most time consuming. Thus, there is a great interest in model reuse and distributed simulation, typified by the High Level Architecture.

Designing manufacturing systems is complex and multi-faceted, with a number of factors coming into play. The larger the system being designed is, the greater the number of factors, decisions, constraints and risks it involves. The system of continuous transport, production and information activities that are a means of ensuring customer needs and market functioning represents a logistics system.

Manufacturing is an activity during which the initial raw materials, processed materials, semi-finished material and some components are similarly converted into products. In other words, the transformation of inputs into outputs is achieved. Manufacturing processes are carried out in manufacturing systems, which represent an ordered collection of resources whose function is the transformation of inputs into desired outputs [23]. To ensure the main manufacturing aims are achieved, namely profit, productivity, efficiency, performance, adaptability, responsiveness, quality and continual improvement of products and services throughout their life cycle the most accurate model possible has to be used.

Interactions of the three elements as logistics industry, logistics infrastructure and logistics operations represent functional basis of the logistic sector as a system [24]. Since random phenomena, like the variability of the cycle time, result in a loss of production rate, the machines in an asynchronous flow production system are usually decoupled with the help of buffers [25]. Many companies want to know the performance of linear flow lines with stochastic processing times and the determination of the optimum buffer configuration [26]. However, analytic models present limitations when modelling and studying a large-scale dynamic logistic system in manufacturing. What would the objective function for the entire 
manufacturing company, e.g., from the field of mining, metallurgy, mechanical engineering, automotive, etc., looks like? It is feasible to capture part of a studied system with a focus on just one machine or workplace but it is difficult if not impossible to examine the system as a larger whole through analytic optimisation. It is necessary to maximise some parts of manufacturing and minimise others. In other cases, criteria, which are neither minimised nor maximised, are considered, e.g., right colour, the right size, right type, etc.

It is clear that to render the activity of a large-scale logistic system in manufacturing as one functioning unit, it is necessary to use simulation systems. The design of the simulation systems depends on the quality of the available data and on a detailed analysis of the system. The modelling of the manufacturing systems requires sufficient knowledge of the manufacturing and its segments and elements and also its limitations and risks. The simulation is carried out with a specific purpose in mind. Therefore, it is necessary to define the aim that will be achieved by the simulation. The aim can differ from the identification of the systems bottlenecks to the streamlining of the systems' activities. The simulation itself does not provide an immediate solution to the problem; it is used to understand the systems behaviour. When the behaviour is known, it is possible to perform the improvements and effective interventions into the system. Those will be subsequently confirmed by the simulation, assuming that the real system is going to react similarly to the simulated one. The compliance of the real system with the simulated one is based on the quality and accuracy of the simulated system. This compliance predetermines the effectiveness of the interventions in the real system $[27,28]$.

\subsection{Hierarchic structure of large-scale logistics system using EXTENDSIM}

Logistics systems consist of a finite number of active elements that create the networks, in which the logistics flows occur. These systems have a stochastic and probabilistic character. Before the design of the simulation model, it is necessary to determine whether it is possible to design the model as a one system or a collection of several individual parts. Many types of simulation software allow for the design of models according to a hierarchic structure, in which the whole large-scale logistics system is represented by one hierarchic block.

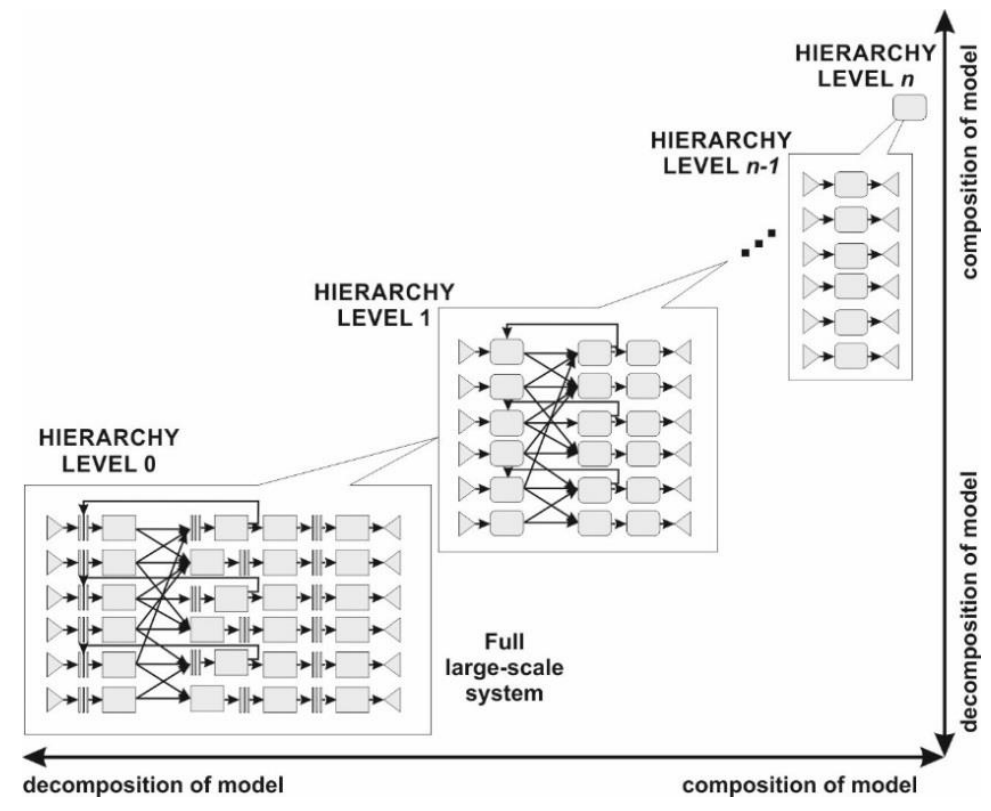

Figure 1: Hierarchic structure of large-scale logistics systems.

The simulation system EXTENDSIM is among the simulation systems. It allows for the design of models of discrete and continuous processes. EXTENDSIM is focussed on events; 
therefore, it is suitable to simulate logistics and manufacturing systems. It is also capable of designing a new block, which consists of a combination of several blocks. These new blocks belong to the hierarchic group [29-31]. The combined blocks allow for the design of structured models and to make the simulation system transparent (see Fig. 1).

The hierarchic block is made from already existing blocks. The block creates a hierarchic group (see Fig. 2).

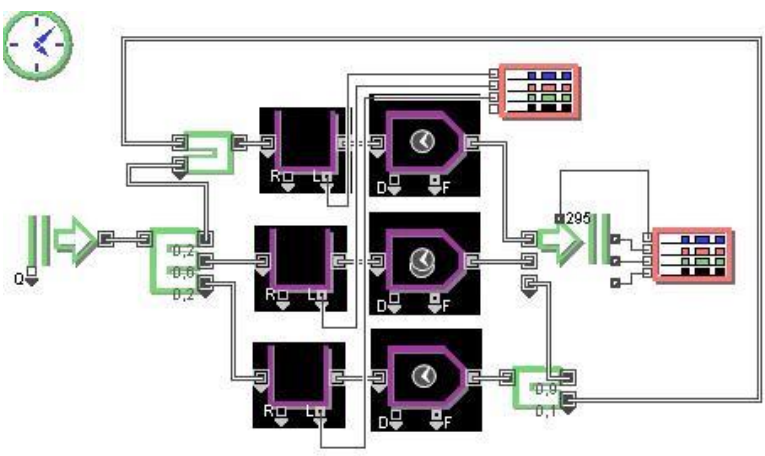

Figure 2: The group of blocks which create the basis of the hierarchic block in a one-level simulation model (EXTENDSIM environment).

After the design of the hierarchic blocks, the original blocks will be transformed into a newly designed hierarchic block, which contains as many inputs and outputs as were constituted blocks and connectors in the original part of the system before their highlighting. For a better identification of the hierarchic block, it is necessary to name it (see Fig. 3). The whole simulation model can be created from only the hierarchic blocks, or alternatively the whole simulation model can consist of just one hierarchic block (see Fig. 4).

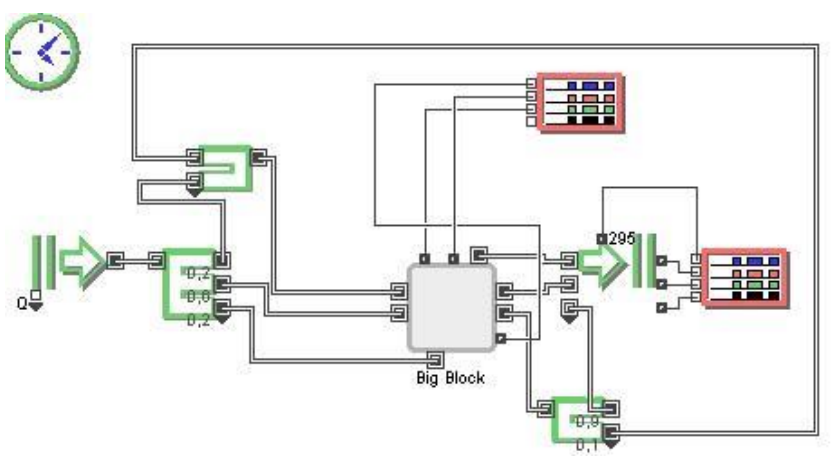

Figure 3: Simulation model with a two-level hierarchic structure (EXTENDSIM environment).

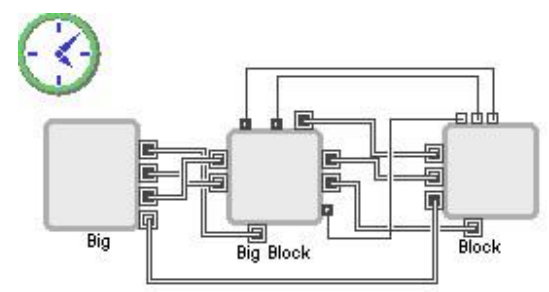

Figure 4: Simulation models with a hierarchic structure (EXTENDSIM environment).

\section{CASE STUDY}

The case study from the automotive industry was carried out to analyse and identify the potential of a computer simulation using a hierarchic structure for increasing the effectiveness of designing large-scale logistics systems in manufacturing. 


\subsection{The creation of the formalised scheme}

Designed large-scale logistics system is concerned with manufacturing of a GDI (Gasoline Direct Injection) pump, a high-pressure fuel pump that is used for a direct injection of fuel under high pressure. It can be used for most types of fuels and engines.

The manufacturing of the GDI pump consists of several working operations:

1) Degreasing and drying. Everything that enters the production line has to be degreased and dried, in order to meet customer requirements both of the customer and of the manufacturing process. All the input components are degreased chemically with the help of ultrasound. Then the elements of the product are chemically cleaned in order to ensure the surface features of the components. Finally, the components are dried in air heated at $110^{\circ} \mathrm{C}$.

2) Welding. The components of the GDI pump are welded together using laser welding technique.

3) Pressure tests. The products have to be tested with electric press machines throughout the manufacturing process. The components are gradually subjected to helium air and pressure tests.

4) Quality test. After the products are completed, they have to undergo tests to ensure their quality and functionality. The products are monitored by security cameras throughout the manufacturing process and afterwards tested by required dynamic and static tests.

The formalised logistics scheme of the GDI pump manufacturing (see Fig. 5) represents the exact succession of the production operations, connection of working places to technical tools and parameters of the material flows according to the volume distribution and time constraints (see Table I). The formalised schema represents the whole system with its components and connections.

It is necessary to realise that according to the logistics and the company as a whole, the main chain (supplying - manufacturing - distribution) is the most important thing. According to the main chain and its computer simulation, it is possible to group the defined parts of the model into a few hierarchic blocks that will represent the main logistics chain.

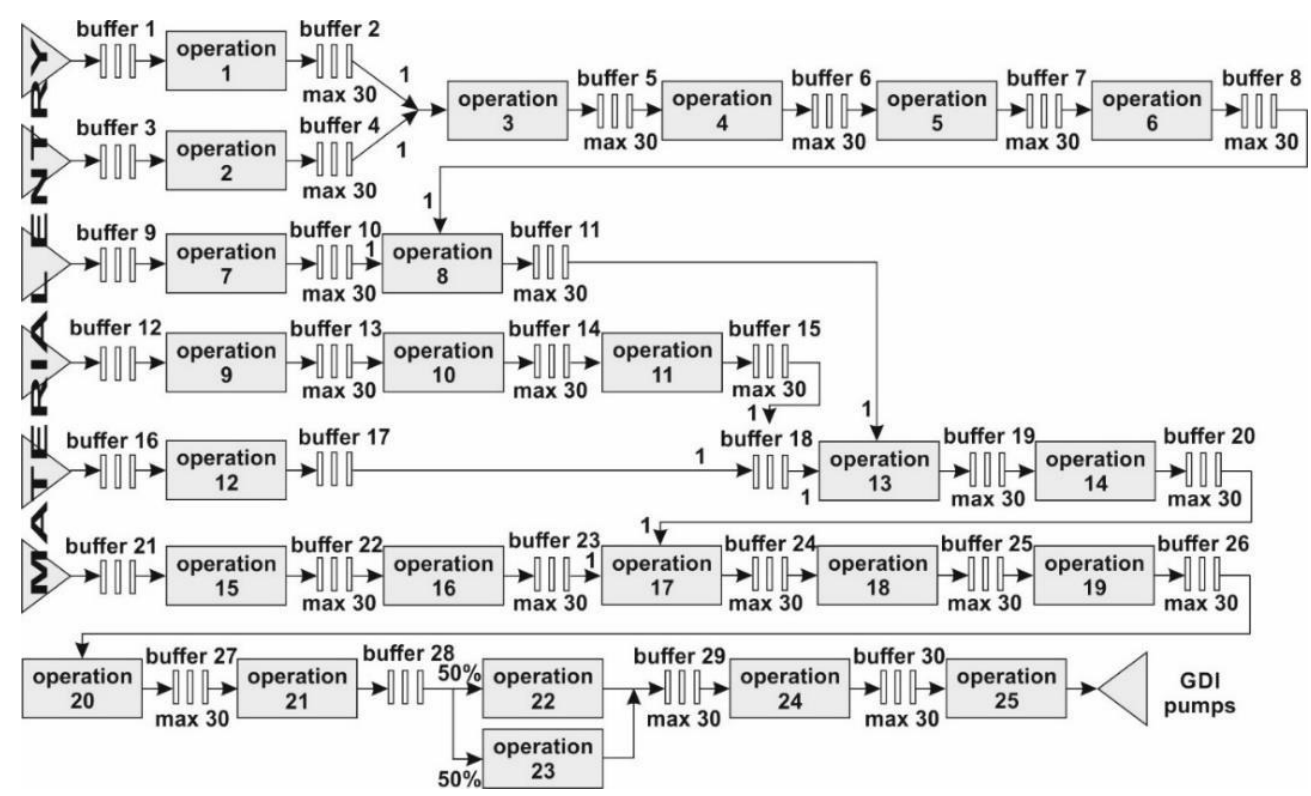

Figure 5: Formalised scheme of the GDI automobile pump.

From the perspective of logistics in manufacturing, this case is considered a flow-shop system, which strictly defines the sequence of the production operations. The study of this system is not affected by the design of a simulation system with the hierarchic structure. The settings and editing of the capacities depends only on the numbers entered into the block's 
parameter settings, which represent the capacity of the given production tool. This item can be set as an integer from 1 to "infinity".

Table I: Manufacturing operations, equipment and production times of operations during the production of the GDI pump.

\begin{tabular}{|c|l|c|}
\hline Operation & Facility & Total time of operation (s) \\
\hline 1 & marposs & 32.0 \\
2 & welder-air pressure test & 38.0 \\
3 & press-welder-air pressure test & 39.0 \\
4 & press-air pressure test- press & 40.0 \\
5 & press-camera-air pressure test & 39.0 \\
\hline 6 & welder-welder & 36.0 \\
7 & press & 30.0 \\
8 & press-welder-air pressure test & 36.0 \\
9 & welder & 35.0 \\
10 & welder & 33.0 \\
\hline 11 & air pressure test & 25.5 \\
12 & press & 12.0 \\
13 & welder-deviation meter & 47.0 \\
14 & camera-welder & 27.5 \\
15 & press & 8.5 \\
\hline 16 & press-camera-welder & 28.0 \\
17 & welder & 38.5 \\
18 & press-welder & 30.0 \\
19 & air pressure test & 37.5 \\
20 & helium pressure test & 40.0 \\
\hline 21 & welder & 38.0 \\
22 & end of line test - A & 55.0 \\
23 & end of line test - B & 55.0 \\
24 & welder-engraving & 38.0 \\
25 & measuring check device & 45.0 \\
\hline
\end{tabular}

\subsection{Hierarchic simulation model design}

The formalised logistics scheme was transformed into computer simulation model (Fig. 6).

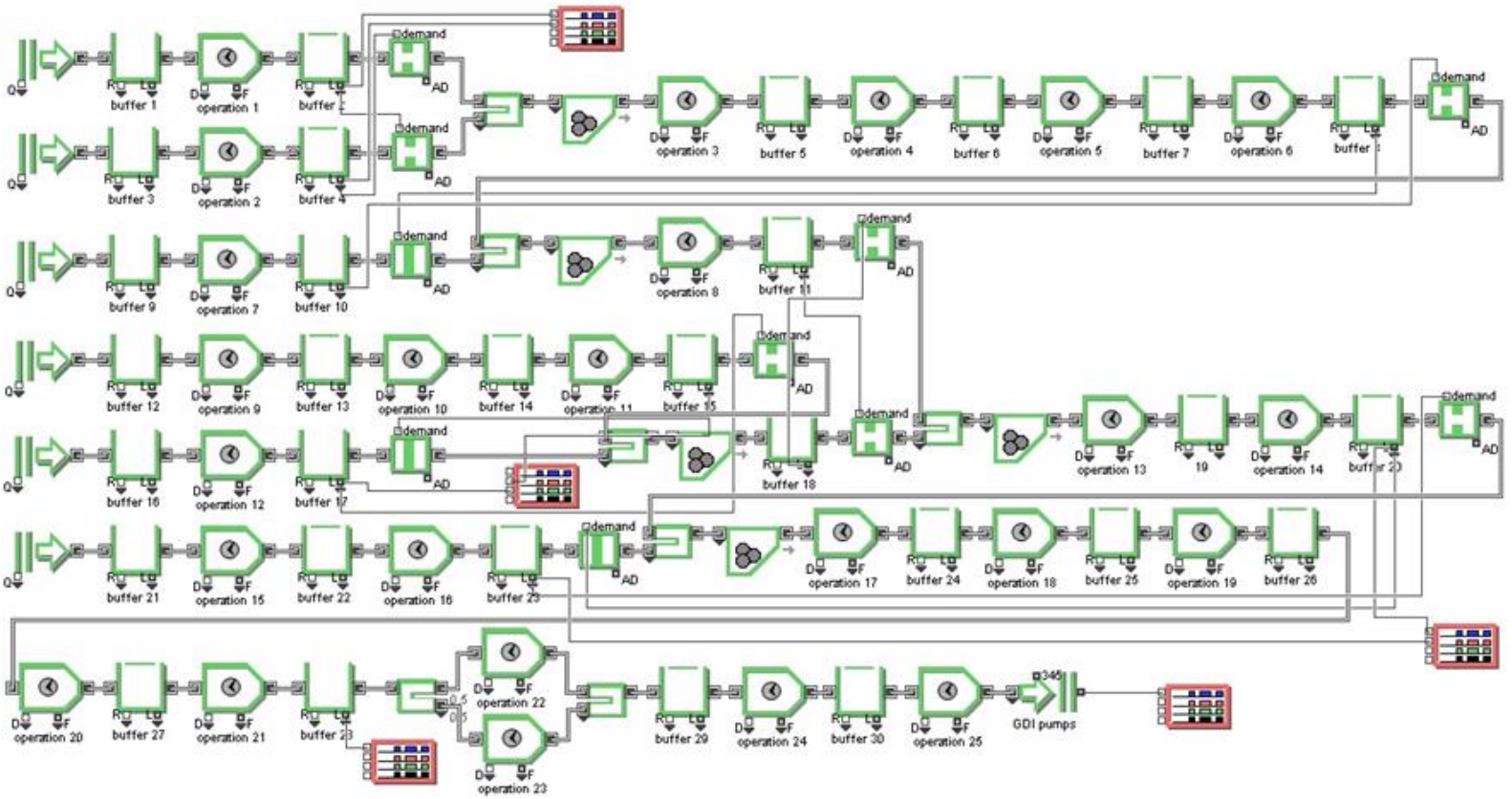

Figure 6: Computer simulation model of the researched large-scale logistics system (EXTENDSIM environment). 
It is necessary to realise that the operation that is represented by the "buffer-operationbuffer" block is far more complex in reality. If it concerns human intervention into the manufacturing, the concrete production operations also consist of parts such as gripping the material, setting the service machine, fitting the material into the machine, running the production tool, removal of the product from the machine, laying the product into the tray, etc. This whole process is represented by one number - the length of the tool, which captures all the partial activities. It follows that the whole system is even more complicated. According to the research, the setting of the system and the identification of the bottlenecks as some kind of simplification of the specific operations is in running order. After identifying the bottlenecks, it is possible to study the specific part and even create a simulation model just for this part. The hierarchic structure of the simulation model allows the user to pass through the individual levels. Double-clicking the hierarchic block will open it in detail (see Figs. 7 and 8) the aggregated part of the production, operations, activities, etc.

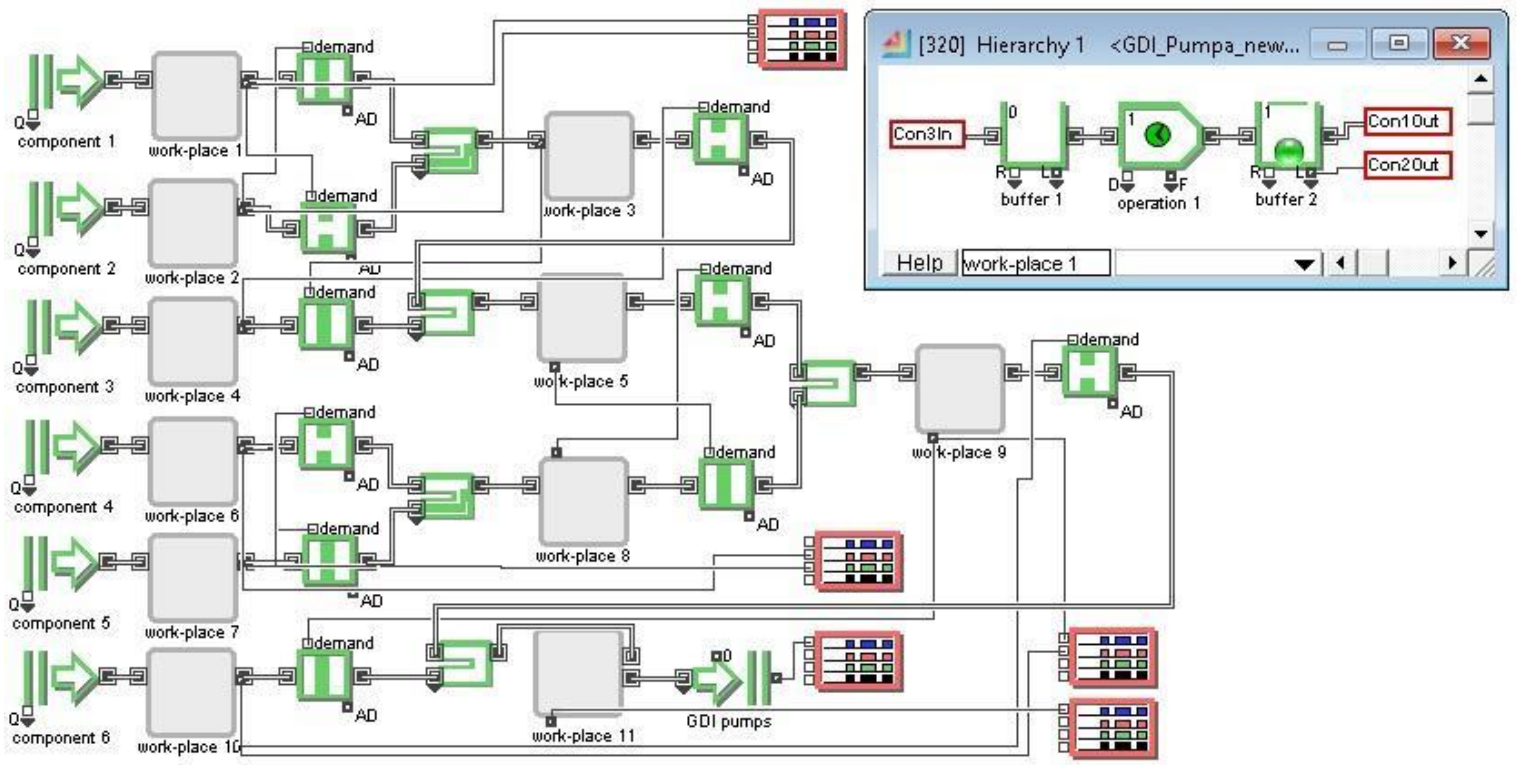

Figure 7: Two-level simulation model using the hierarchic structure (EXTENDSIM environment).
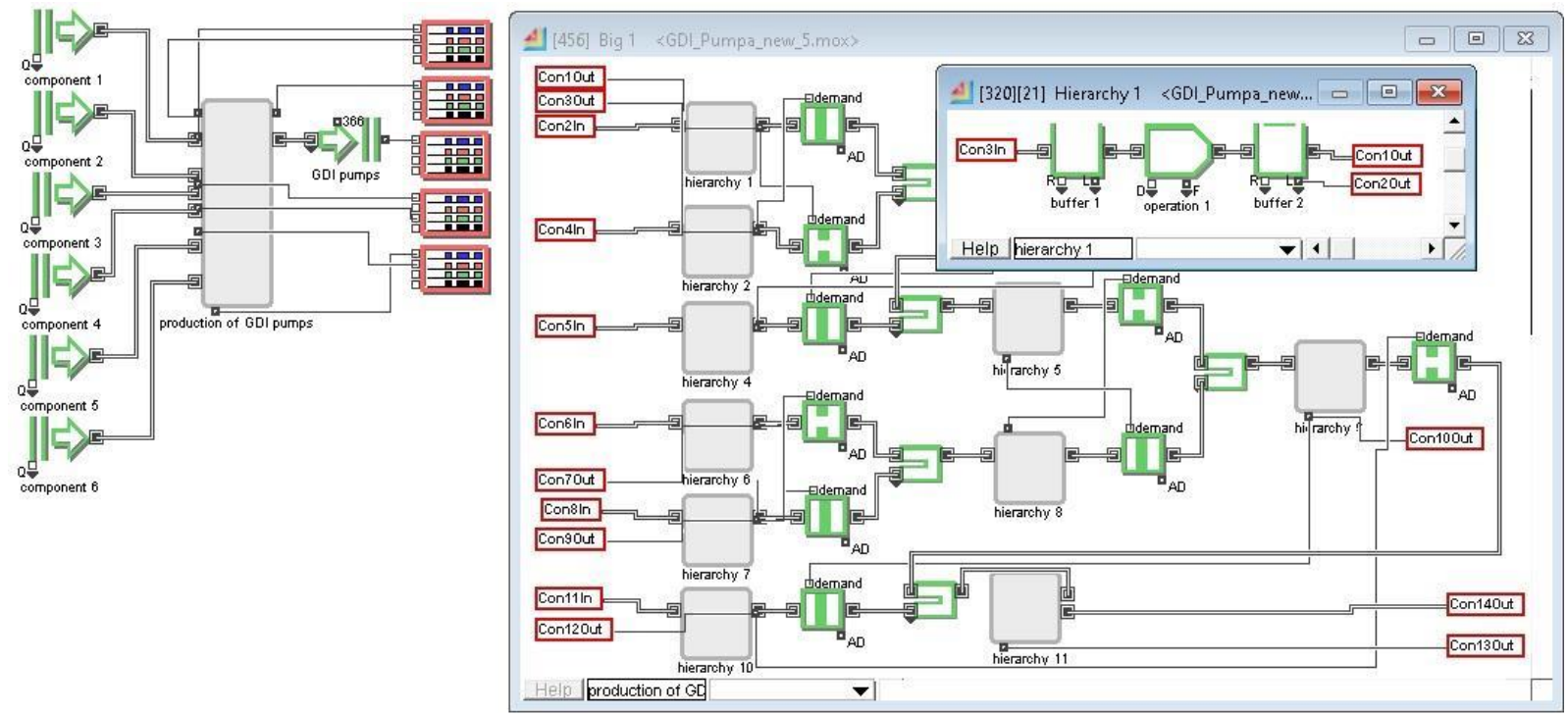

Figure 8: Three-level simulation model using the hierarchic structure (EXTENDSIM environment). 


\subsection{Streamlining of the researched system through the hierarchic simulation model}

The results of the computer simulation prove that the system has bottlenecks in several parts. The current state is confirmed by the actual activity of the company. Within the defined simulation, the activity of the system is investigated during one working shift, which is 7.25 hours long.

From running the simulation, it is clear that connecting the elements into one piece (mounting of the GDI pump components) is affected by the previous operation. A wait for the missing component occurs. Therefore, some buffers have a usage of 0.00 and others 1.00 . This case can be seen within the operations 3, 8, 13 and 17 (see Table II).

Table II: Utilisation of buffers and facilities of GDI pumps production.

\begin{tabular}{|c|c|c|c|c|}
\hline Buffer & $\begin{array}{c}\text { Buffer } \\
\text { utilisation }\end{array}$ & Operation & Facility & $\begin{array}{c}\text { Facility } \\
\text { utilisation }\end{array}$ \\
\hline 1 & 0.79 & 1 & marposs & 0.85 \\
\hline 3 & 0.00 & 2 & welder-air pressure test & 1.00 \\
\hline 2 & 1.00 & \multirow{2}{*}{3} & \multirow{2}{*}{ press-welder-air pressure test } & \multirow{2}{*}{1.00} \\
\hline 4 & 0.00 & & & \\
\hline 5 & 0.97 & 4 & press-air pressure test- press & 1.00 \\
\hline 6 & 0.00 & 5 & press-camera-air pressure test & 0.97 \\
\hline 7 & 0.00 & 6 & welder-welder & 0.89 \\
\hline 9 & 0.00 & 7 & press & 1.00 \\
\hline 10 & 1.00 & \multirow{2}{*}{8} & \multirow{2}{*}{ press-welder-air pressure test } & \multirow{2}{*}{0.89} \\
\hline 8 & 0.00 & & & \\
\hline 12 & 0.00 & 9 & welder & 1.00 \\
\hline 13 & 0.00 & 10 & welder & 0.94 \\
\hline 14 & 0.00 & 11 & air pressure test & 0.73 \\
\hline 16 & 0.00 & 12 & press & 1.00 \\
\hline 11 & 0.01 & \multirow{4}{*}{13} & \multirow{4}{*}{ welder-deviation meter } & \multirow{4}{*}{0.99} \\
\hline 17 & 1.00 & & & \\
\hline 15 & 0.00 & & & \\
\hline 18 & 1.00 & & & \\
\hline 19 & 0.00 & 14 & camera-welder & 0.58 \\
\hline 21 & 0.99 & 15 & press & 0.20 \\
\hline 22 & 1.00 & 16 & press-camera-welder & 0.62 \\
\hline 23 & 1.00 & \multirow{2}{*}{17} & \multirow{2}{*}{ welder } & \multirow{2}{*}{0.81} \\
\hline 20 & 0.00 & & & \\
\hline 24 & 0.00 & 18 & press-welder & 0.63 \\
\hline 25 & 0.00 & 19 & air pressure test & 0.79 \\
\hline 26 & 0.00 & 20 & helium pressure test & 0.84 \\
\hline 27 & 0.00 & 21 & welder & 0.79 \\
\hline \multirow{2}{*}{28} & \multirow{2}{*}{0.97} & 22 & end of line test $-\mathrm{A}$ & 0.77 \\
\hline & & 23 & end of line test $-B$ & 0.73 \\
\hline 29 & 0.18 & 24 & welder-engraving & 0.51 \\
\hline 30 & 0.03 & 25 & measuring check device & 0.61 \\
\hline
\end{tabular}

The buffers, whose maximal capacity is 30 pieces, have an additional effect on the load efficiency of the system. It causes a decrease in the system's speed because the succession and cadence of the production depends on the chain of all tools. This creates the situations, when one tool is not fully used, but its buffer is full. This is caused by the subsequent buffer also being full, so the previous one cannot be emptied, resulting in the tool's downtime. This case can be seen within the operations 15 and 16 (see Table II). 
The streamlining of this particular system is also more difficult because the whole manufacturing depends on supplying the essential parts of the production. Consequently, even a radical resetting of the production capacity of the production tool does not mean an increase in the manufactured elements. It only causes the reduction of the tool's usage. Therefore, if we want to increase the production capacity within these conditions, we also have to increase the supply of the input components. This large-scale logistics system in manufacturing should be solved through the hierarchic blocks that are more transparent and allow for the representation of the whole system in parts. Here, we apply the principle of the "black boxes". We streamline the activity of one "black box", and we know that we have streamlined a specific part of the manufacturing process. Later on, we only focus on the inputs and outputs. After we set all the hierarchic components of one "black box", the whole logistics system would also be set. At the current state the system is capable of producing 340-350 pieces per shift (see Fig. 9).

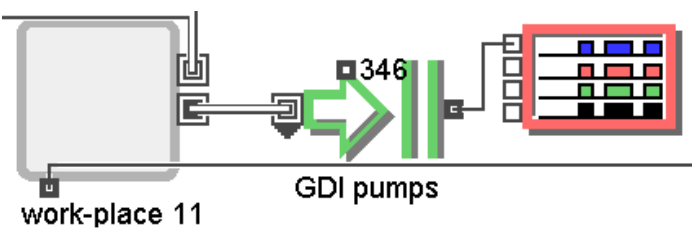

Figure 9: Production of the GDI pumps before the system's streamlining.

In the case of a system, where there is mounting and connecting of the pieces into a larger product, it is necessary to time the input of the individual components of the finished product, or where applicable their mutual, equal tempo. It is ideal that the components that meet on one place are the same components that create the whole product and the same components that are going to undergo the mounting process. Other cases only create waiting times and downtimes. From the analysis of the buffer's usage it follows that the least used tool (the tool with the biggest number of downtimes) is "operation 15 - press". The buffer before this tool "buffer 21 " is used on $99 \%$. This means that the shortage on the "operation 15 " is caused by the following element, which is blocking the tools before it. There is no mistake in the supply, but in the activity of the manufacturing process.

Other elements of the system with lower usage are the end elements of the whole chain, operations $18-25$. Operations $18-21$ have zero buffers usage, the operations 22 and 23 use their buffers at $97 \%$, and the operations 24 and 25 use their buffers at $18 \%$ and $3 \%$ respectively. This means that the bottlenecks occur during operations 22 and 23, "end of line test A, B" (see Table II). By raising the operational efficiencies of those operations by $100 \%$, e.g., by buying more tools or speeding up the "end of line tests A, B, C and D", it is possible to raise the performance of the whole system to the $\approx 535-545$ pieces per shift (see Fig. 10), which is $\approx 56 \%$ more than the performance of the original system.

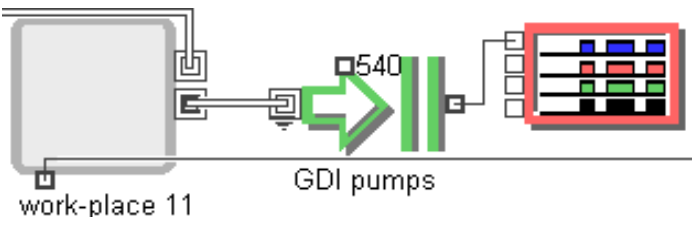

Figure 10: Production of the GDI pumps after the system's streamlining.

Another reinforcement of checking tools does not change the tempo or the capacity of the output production. It means that the bottleneck is somewhere else in the system. It also means that any intervention into the system's other parts without streamlining the end performance tools does not increase the production, just the downtimes within the system. 
After setting the hierarchic element "work-place 11", the next bottleneck seems to be the position "work-place 9". Based on the elements that create the hierarchic block, "buffer 19" and "buffer 20" have a usage of $0 \%$ and the "operation 14" is only used around $60 \%$, while the "operation 13" is used at $99 \%$. This follows that the bottleneck is the work place "welderdeviation meter". If we reinforce this position with other tools, it is possible to increase the performance of the system by another $5.5 \%$, making it $61.4 \%$ in total, which means $\approx 565$ pieces produced per shift. Another study has proven that a lot of buffers from other places are loaded to the maximum capacity (see Fig. 11). It means the company would have to buy more tools, which often means investing several million euros. Therefore, the best solution is to reinforce the checking tools at the output, which will cost less and bring a certain reinforcement of the whole system.
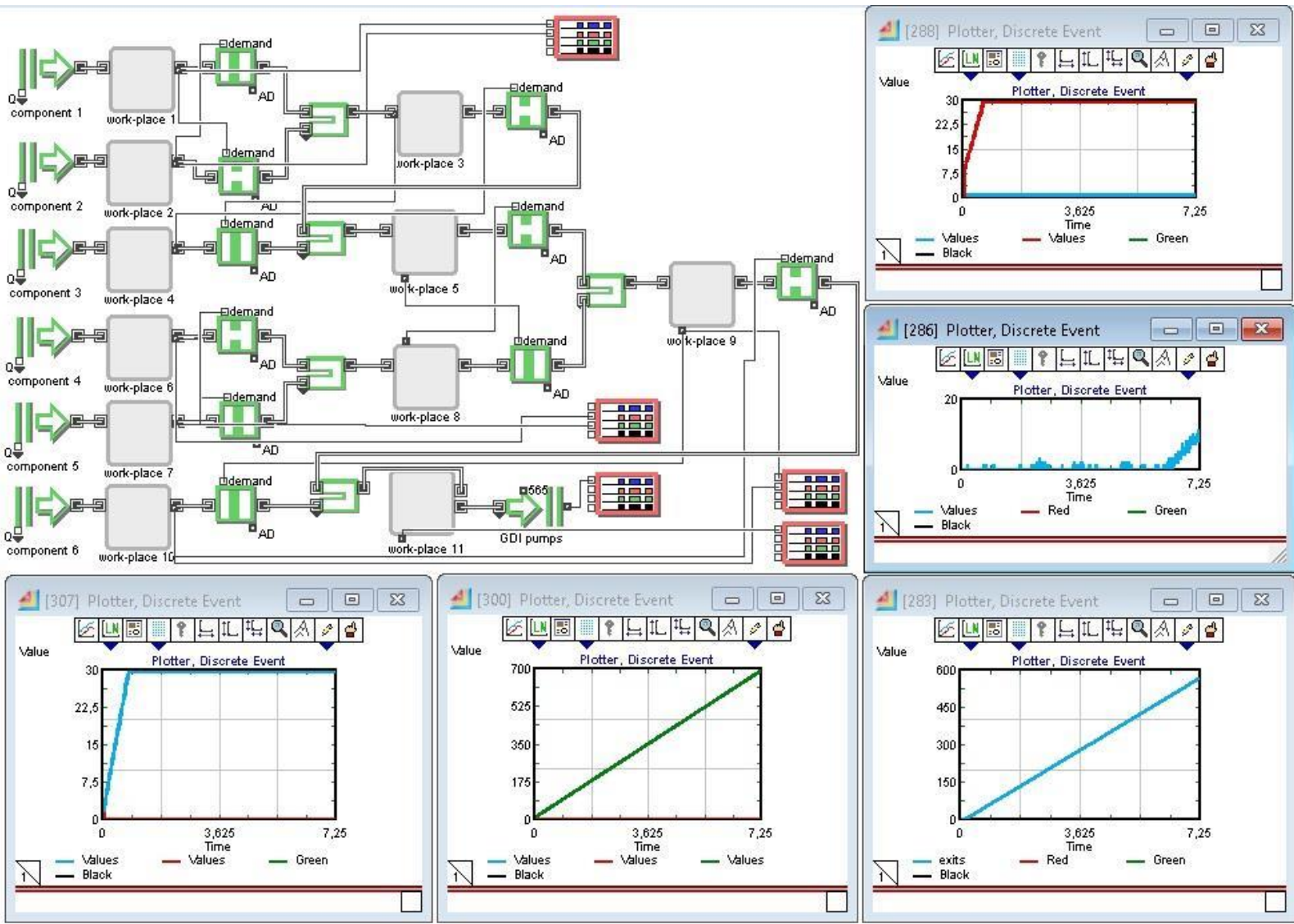

Figure 11: Production of the GDI pumps after setting the system.

\section{CONCLUSIONS AND OPEN OUESTIONS}

The use of a hierarchic structure to study large-scale logistic systems in manufacturing allows a real-world practical application of a computer simulation for streamlining the systems. Another advantage of this kind of computer simulation is a faster understanding of the whole system and a simplified identification of the bottlenecks. The user can also use the possibility of partial streamlining. The savings gained can be repeatedly used for streamlining of other parts of the system. The implementation of the results in practice can represent million-euro investments, which the company cannot afford. Therefore, the continuous application of the results can be a better solution in practice.

According to our opinion the computer simulation using a hierarchy structure is a fundamental approach for current trend, leading to the design of "digital twins". A "digital twin" represents a virtual copy of a real production, while the real system is continuously 
monitored and observed with its output, running and input data. The data are then applied in real time and are evaluated on the "digital twin". The digital twin is used to set the system and verify the hypotheses to look for the effective and optimal settings of the whole system. Then the data is transferred to the real system. This process is continuously repeated and therefore the real and the virtual systems always controlled in real time. A similar approach is used within every simulation, but the data are not transferred in real time but with some delay, meaning some kind of lag in verifying the data in practice.

Among the disadvantages remains the need for physical intervention into the specific production in the case of solving some technical issues, e.g. replacing specific manufacturing tools, changing the working place for a flow-shop or, if applicable, job-shop systems, performance of some general repairs, etc. All the shortcomings can be assumed by monitoring the system in real time, making it possible to assume an actual general repair of even to simulate it and plan it.

From the above-mentioned, there are still some unanswered question and possibilities in the further investigations:

1) How to secure back-up of the actual manufacturing? Through the staff or duplication of the tools?

2) Are those not just useless manufacturing capacities? How to use them as tools for a short-term increase of the production capacity?

3) How will the "digital twin" and computer simulations realise the requirements of the market in real time?

In logistics terms, some questions dealing with the basic postulates of logistics also arise, but those will be dealt in the authors' future research work.

\section{ACKNOWLEDGEMENT}

The work was supported by the specific university research of Ministry of Education, Youth and Sports of the Czech Republic at SKODA AUTO University No. SGS/2015/02 and the project "Implementation of new methods and forms of education based on applied research in the field of study 8.5.1 Logistics" KEGA 056TUKE-4/2018, funded by the Slovak Cultural and Educational Grant Agency, KEGA Programme.

\section{REFERENCES}

[1] Rabe, M.; Spieckemann, S.; Wenzel, S. (2008). A new procedure model for verification and validation in production and logistics simulation, Proceedings of the 2008 Winter Simulation Conference, 1717-1726

[2] Coyle, J. J.; Langley Jr., C. J.; Novack, R. A.; Gibson, B. J. (2013). Supply chain management: A logistics perspective, $9^{\text {th }}$ edition, South-Western, Cengage Learning, Mason

[3] Habchi, G.; Berchet, C. (2003). A model for manufacturing systems simulation with a control dimension, Simulation Modelling Practice and Theory, Vol. 11, No. 1, 21-44, doi:10.1016/S1569-190X(02)00097-7

[4] Disney, S. M.; Naim, M. M.; Towill, D. R. (1997). Dynamic simulation modelling for lean logistics, International Journal of Physical Distribution and Logistics Management, Vol. 27, No. 3/4, 174-196, doi:10.1108/09600039710170566

[5] Pidd, M. (2004). Computer Simulation in Management Science, $5^{\text {th }}$ edition, John Wiley \& Sons, Chichester

[6] Rotab Khan, M. R.; Harlock, S. C.; Leaf, G. A. V. (1999). Computer simulation of production systems for woven fabric manufacture, Computers \& Industrial Engineering, Vol. 37, No. 4, 745-756, doi:10.1016/S0360-8352(00)00009-7

[7] Zülch, G.; Jonsson, U.; Fischer, J. (2002). Hierarchical simulation of complex production systems by coupling of models, International Journal of Production Economics, Vol. 77, No. 1, 39-51, doi:10.1016/S0925-5273(01)00198-0 
[8] Pekarčíková, M.; Trebuňa, P.; Markovič, J. (2015). Simulation as part of industrial practice, Acta Logistica, Vol. 2, No. 2, 5-8, doi:10.22306/al.v2i2.36

[9] Shymchenko, A. V.; Tereshchenko, V. V.; Ryabov, Y. A.; Salkutsan, S. V.; Borovkov, A. I. (2017). Review of the computational approaches to advanced materials simulation in accordance with modern advanced manufacturing trends, Materials Physics and Mechanics, Vol. 32, No. 3, 328-352, doi:10.18720/MPM.3232017_14

[10] Jia, Z.; Lu, X.; Wang, W.; Jia, D.; Wang, L. (2011). Design and implementation of lean facility layout system of a production line, International Journal of Industrial Engineering, Vol. 18, No. 5, 260-269

[11] Kozina, A.; Pieczonka, A. (2017). Structural determinants of conflicts within the logistics system of an enterprise, Acta Logistica, Vol. 4, No. 2, 19-22, doi:10.22306/al.v4i2.4

[12] Gracanin, D.; Lalic, B.; Beker, I.; Lalic, D.; Buchmeister, B. (2013). Cost-time profile simulation for job shop scheduling decisions, International Journal of Simulation Modelling, Vol. 12, No. 4, 213-224, doi:10.2507/IJSIMM12(4)1.237

[13] Jurčišin, R.; Šebo, J. (2015). Basic production scheduling concept software application in a deterministic mechanical production environment, Acta Simulatio, Vol. 1, No. 4, 1-4

[14] Bohács, G.; Semrau, K. F. (2012). Automatic visual data collection in material flow systems and the application to simulation models, Logistics Journal, Vol. 2012, No. 1, 7 pages, doi:10.2195/li_NotRev_bohacs_de_2012_01

[15] Małkus, T. (2017). Assumptions of trust in logistics cooperation, Acta Logistica, Vol. 4, No. 3, 14, doi:10.22306/al.v4i3.6

[16] Barber, K. D.; Dewhurst, F. W.; Burns, R. L. D. H.; Rogers, J. B. B. (2003). Business-process modelling and simulation for manufacturing management: A practical way forward, Business Process Management Journal, Vol. 9, No. 4, 527-542, doi:10.1108/14637150310484544

[17] Terzi, S.; Cavalieri, S. (2004). Simulation in the supply chain context: a survey, Computers in Industry, Vol. 53, No. 1, 3-16, doi:10.1016/S0166-3615(03)00104-0

[18] Filip, F.-G., Leiviskä, K. (2009). Large-Scale Complex Systems, Nof, S. Y. (Ed.). Springer Handbook of Automation, Springer, Berlin, 619-638, doi:10.1007/978-3-540-78831-7 36

[19] Lu, R. F.; Petersen, T. D.; Storch, R. L. (2007). Modeling customized product configuration in large assembly manufacturing with supply-chain considerations, International Journal of Flexible Manufacturing Systems, Vol. 19, No. 4, 685-712, doi:10.1007/s10696-008-9041-0

[20] Chen, K. W.; Storch, R. L. (2013). Mass Customized Large Scale Production System with Learning Curve Consideration, Emmanouilidis, C.; Taisch, M.; Kiritsis, D. (Eds.). Advances in Production Management Systems. Competitive Manufacturing for Innovative Products and Services, APMS 2012, IFIP Advances in Information and Communication Technology, Vol. 397, Springer, Berlin, 318-325, doi:10.1007/978-3-642-40352-1_40

[21] Santner, T. J.; Williams, B. J.; Notz, W. I. (2003). The Design and Analysis of Computer Experiments, $1^{\text {st }}$ edition, Springer-Verlag, New York, doi:10.1007/978-1-4757-3799-8

[22] Balci, O. (1994). Validation, verification, and testing techniques throughout the life cycle of a simulation study, Annals of Operations Research, Vol. 53, No. 1, 121-173, doi:10.1007/BF02136828

[23] Zhao, J. Y.; Wang, Y. J.; Xi, X.; Wu, G. D. (2017). Simulation of steel production logistics system based on multi-agents, International Journal of Simulation Modelling, Vol. 16, No. 1, 167-175, doi:10.2507/IJSIMM16(1)CO4

[24] Stanković, R.; Šafran, M.; Božić, D. (2016). Guidelines for improving logistic performances as drivers of the logistic industry development, Technical Gazette, Vol. 23, No. 5, 1497-1503, doi:10.17559/TV-20141016184435

[25] Talib Bon, A.; Rahman, A. A.; Bolhassan, E. A.; Nordin, M. A. A. (2013). Optimize assembly production line using line balancing, Proceedings of the $2^{\text {nd }}$ International Conference on Global Optimization and its Applications, 140-145

[26] Gingu (Boteanu), E. I.; Zapciu, M.; Cavalieri, S. (2017). Production systems flow modelling using decomposition method and required buffers, International Journal of Simulation Modelling, Vol. 16, No. 2, 207-218, doi:10.2507/IJSIMM16(2)2.367 
[27] Straka, M.; Malindzakova, M.; Rosova, A.; Trebuna, P. (2016). The simulation model of the material flow of municipal waste recovery, Przemysl Chemiczny, Vol. 95, No. 4, 773-777, doi: $10.15199 / 62.2016 .4 .12$

[28] Groover, M. P. (2007). Automation, Production Systems, and Computer-Integrated Manufacturing, $3^{\text {rd }}$ edition, Prentice Hall, Upper Saddle River

[29] Straka, M. (2007). Discrete and continuous simulation in simulation language Extend, $1^{\text {st }}$ edition, Edičné stredisko/AMS, Košice (in Slovak)

[30] Straka, M. (2017). Teoretické východiská simulácie - simulačný systém EXTENDSIM 9.x, The theoretical basis of simulation - simulation system EXTENDSIM 9.x, $1^{\text {st }}$ edition, Edičné stredisko/AMS, Košice (in Slovak)

[31] Stangova, A. (2014). Programming of methods for the needs of logistics distribution solving problems, Acta Logistica, Vol. 1, No. 2, 15-18, doi:10.22306/al.v1i2.17 